\title{
A Prospective Six Sigma Quality Improvement Trial to Optimize Universal Screening for Genetic Syndrome Among Patients With Young-Onset Colorectal Cancer
}

Sean Dineen, MDª Patrick M. Lynch, JD, MD ; Miguel A. Rodriguez-Bigas, MDª; Sarah Bannon, MS, CGC Melissa Taggart, MDc; Colleen Reeves, RN, CNPa; Cathy Modaro, MS'; Michael Overman, MD; George J. Chang, MDa; John M. Skibber, MDa; and Y. Nancy You, MD, MHSc ${ }^{a}$

\begin{abstract}
Background: Improving the quality of health care is a national priority, and providing patient-centered care is one of the 6 key areas for quality improvement. In the setting of patients with young-onset colorectal cancer (CRC), appropriate genetic workup and testing for potential underlying inherited CRC syndromes is fundamental to patient-centered care. Lynch syndrome (LS) is the most common of these inherited syndromes, and current recommendations from the NCCN and other professional societies advocate universal screening for LS among young patients with CRC. However, practical implementation of these guidelines often falls short. Methods: We conducted a prospective quality improvement intervention trial to optimize universal screening for LS in young (age $<50$ years) patients, involving 356 eligible patients during the 12-month preintervention period and 299 patients during the postintervention. Results: Applying the Six Sigma conceptual framework, we demonstrated a significant increase in use of tumor-based molecular testing and subsequent confirmatory germline mutation testing for LS. This led to identification of more patients to be managed as having LS and of more first- and second-degree relatives to benefit from the testing results. Conclusions: This study demonstrated the successful application of a quality improvement conceptual framework for the universal adoption of molecular biomarker testing in patients with cancer, and for improving adherence to NCCN Clinical Practice Guidelines in Oncology for CRC Screening. As molecular and genetic testing is becoming increasingly common, we present a prototype study for improving the adoption of molecular studies and the provision of guideline-based patient-centered care. (J Natl Compr Canc Netw 2015;13:865-872)
\end{abstract}

\section{Background}

The 2001 Institute of Medicine (IOM) report, "Crossing the Quality Chasm," has made improving the quality of health care a national priority. ${ }^{1}$ One of the $6 \mathrm{IOM}$ focus areas was provision of patient-centered care. ${ }^{1}$ It emphasizes care that is respectful of and responsive to the individual patient and their needs, and clinical decisions that are guided by values of the individual. ${ }^{1}$

Adults younger than 50 years currently constitute the only population segment in the United States in which the incidence of colorectal cancer (CRC) is increasing. ${ }^{2-5}$ For these young patients, patient-centered care should include an investigation of whether there is an underlying genetic syndrome that predisposes them

From the Departments of aSurgical Oncology, ${ }^{\mathrm{b}}$ Gastroenterology and Hepatology, 'Pathology, 'Quality Improvement, and eMedical Oncology, The University of Texas MD Anderson Cancer Center, Houston, Texas. Submitted August 23, 2014; accepted for publication April 4, 2015. The authors have disclosed that they have no financial interests, arrangements, affiliations, or commercial interests with the manufacturers of any products discussed in this article or their competitors. to CRC at a young age. ${ }^{6,7}$ The most common hereditary syndrome is Lynch syndrome (LS). Patients with LS face elevated lifetime risks for CRC and other cancers, including endometrial, gastric, small bowel, hepatobiliary, and urothelial cancers. ${ }^{8,9}$ Identification of LS in a young patient with CRC provides them with knowledge regarding cancer risks and enables individualized decisions about genetic testing, cancer surveillance, and risk prevention strategies. ${ }^{9}$

The diagnosis of LS does not rely solely on phenotype recognition. Indeed, LS-associated CRC exhibits a distinct molecular signature: DNA mismatch repair deficiency (dMMR). dMMR can be reliably detected by immunohistochemical studies (IHC) and microsatellite 
instability assays (MSI) performed on CRC tumor tissue. Currently, increasing efforts are being made to screen CRC for dMMR as a way to identify patients at risk for LS and who would benefit from confirmatory germline testing. ${ }^{9-12}$ The cost-effectiveness of this approach has been suggested in analytic models. ${ }^{8,13,14}$ The NCCN Clinical Practice Guidelines in Oncology (NCCN Guidelines) for CRC Screening have evolved to place increasing emphasis on molecular testing for detection of hereditary cancer syndromes, specifically testing for MMR deficiency. ${ }^{15}$ The current NCCN Guidelines suggest either universal testing of all CRC tumors, or the testing of all patients younger than 70 years and selective testing of patients aged 70 years and older who meet Bethesda criteria. ${ }^{6,15-18}$ There had been long-standing and well-publicized recommendations for MMR status testing in all patients aged 50 years or younger with CRC..${ }^{19}$ In addition, knowledge of the dMMR status of CRC helps provide prognostic information and may alter the choice of chemotherapy regimens. ${ }^{20}$ However, in practice, adherence to this guideline is poor, ${ }^{21,22}$ and many patients are not referred for genetic counseling and workup. ${ }^{23}$ We hypothesized that system-based practice intervention, designed with the Six Sigma quality improvement conceptual framework, would improve adherence to NCCN Guidelines and optimize tumor-based screening for LS in young adults with CRC.

\section{Methods}

\section{Study Design and Conceptual Framework}

The aim of this prospective quality improvement trial was to optimize the implementation of universal genetic screening among patients with young-onset CRC. The trial was designed within the conceptual framework of Six Sigma quality improvement. The Six Sigma method focuses on reducing variability and error. The overall goal is to reduce error to below 6 standard deviations (six sigma) of the process mean, ${ }^{24-26}$ representing 3.4 defects per million opportunities (DPMO). ${ }^{25,27}$ Using bile duct injury during cholecystectomy as an example, the current rate of 1 injury per 1500 cases equals $95 \mathrm{DPMO}$, or 5.25 sigma. To achieve six sigma, the rate would need to be reduced to 1 injury per 45,000 cases. $^{25,28}$ This is achieved through continuous cycles of process control that identify areas where variability can be reduced.
The core tool used to drive Six Sigma projects is the Define-Measure-Analyze-Improve-Control (DMAIC) cycle, a 5-step data-driven process used for improving, optimizing, and stabilizing processes (Figure 1).25,29 The quality improvement trial was conducted within the structure of The University of Texas MD Anderson Cancer Center (MDACC) Clinical Safety and Effectiveness (CS\&E) program. The CS\&E collaborative was designed to integrate quality improvement and patient safety into the daily fabric of caring for patients by providing the knowledge, skills, and support needed to implement practice-improvement initiatives.

All participants were recruited from the Gastrointestinal and CRC Patient Care Centers at MDACC. These centers encompass multidisciplinary care providers from surgical oncology, medical oncology, gastroenterology, radiation oncology, and internal medicine.

\section{Process Analysis}

A dedicated study team was assembled, including multidisciplinary representation from gastroenterology (P.M.L.), surgical oncology (M.A.R.B., C.R., G.J.C., J.M.S., Y.N.Y.), medical oncology (M.O.), and genetic counseling (S.B.).

Based on the DMAIC conceptual framework, we first examined the existing process of care for young pa-

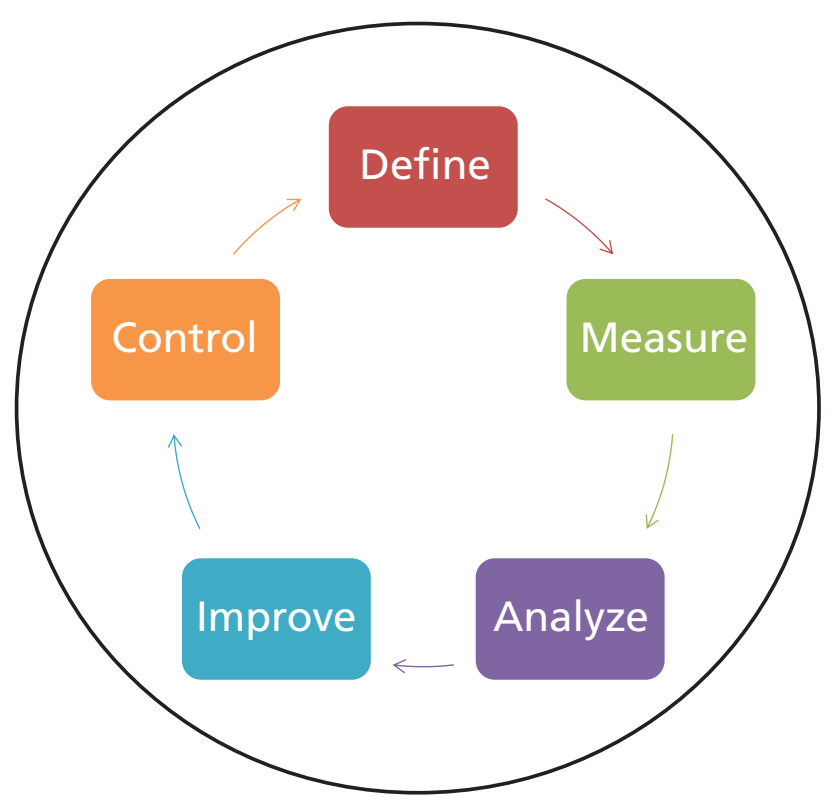

Figure 1 Six Sigma conceptual framework. Six Sigma is a methodology widely used in the industry. The goal is to reduce the error rate (termed defects) to $<6$ standard deviations (sigma) from the mean. The cornerstone of Six Sigma is the Define-Measure-Analyze-Improve-Control (DMAIC) cycle, as illustrated. The critical component of continuous quality improvement is the continuous, cyclic nature of the process. ${ }^{23-26}$ 
QI Trial for Genetic Screening

tients (age, 18-50 years) patients diagnosed with CRC. Flow-charting was used to define the boundaries of the process, to start with histologic diagnosis of CRC and to end with confirmatory germline testing for LS. We identified that individual providers ordered IHC and/or MSI for dMMR at their own discretion, and that referral to genetic counseling for risk assessment, counseling, and/or germline testing was nonuniform and depended on individual clinician's choice.

Next, a cause-and-effect analysis was performed to identify barriers to universal tumor-based screening for LS. A fish-bone diagram (Figure 2) was constructed by members of the quality improvement team to enumerate reasons for missed opportunities for LS testing, including patient-related (eg, fear of genetic testing), pathology-related (eg, unavailability of adequate tumor tissue), and provider-related factors (eg, failure to order tumor testing or difficulty and confusion related to the ordering process). Provider failure to order tumor testing was identified by the team as the main contributor to the existing variation in the practice. Thus, we defined the aim of the quality improvement trial to increase the proportion of patients with young-onset CRC who had tumor studies for dMMR ordered, with the ultimate target of $100 \%$ or universal screening.

\section{Intervention}

The trial intervention was designed to gain multidisciplinary buy-in and to result in a cultural shift toward the new standard of care of universal tumor-based screening for LS. The intervention consisted of 3 primary components. The first component involved active identification of the target patient population (ie, all patients with CRC aged $\leq 50$ years) at the time of new patient registration. An education pamphlet regarding LS was automatically included in the registration packet. Visual posters were placed in the registration rooms to prompt patients to inquire about genetic syndromes. The second component involved educating members of the multidisciplinary team with regard to universal tumor screening as a new standard of care for young patients with CRC. Members of our study team provided education to their peer groups through various forums: physicians at the multidisciplinary tumor board; midlevel providers and nursing staff at in-service seminars; and genetic counselors to administrative support staff at the care centers. The third component involved placing visual cues on all computers throughout the care centers to serve as reminders at the point-of-care (Figure 3). A start date was set, after which all new patients with CRC between 18 and 50 years of age were to

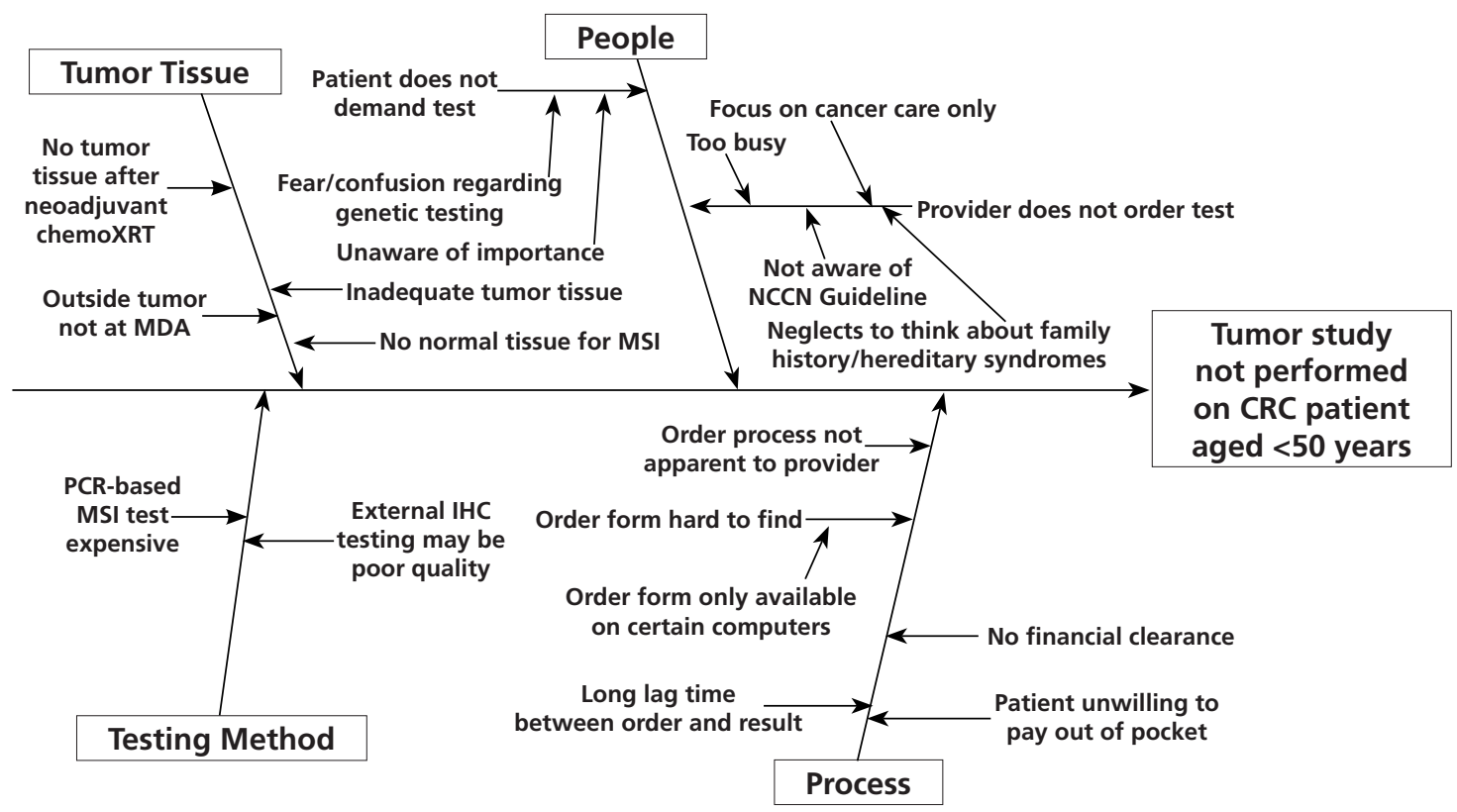

Figure 2 Fishbone diagram. To identify contributing barriers to universal tumor-based molecular screening in young-onset patients with CRC, a fishbone diagram was created by the multidisciplinary study team.

Abbreviations: chemoXRT, chemoradiation therapy; CRC, colorectal cancer; IHC, immunohistochemistry; MDA, MD Anderson; MSI, microsatellite instability assay; PCR, polymerase chain reaction. 
undergo universal screening for LS through tumor MMR testing; these patients constituted the postintervention group. A real-time audit was performed for 3 months after the start date. All eligible target patients were prospectively reviewed biweekly to determine whether tumor MMR testing was ordered. If tumor testing had not been ordered, a standardized e-mail reminder was sent to the treating team and/ or they were asked to indicate a specific reason why the patient may opt out of universal MMR testing. No additional incentive or sanction was provided for compliance or noncompliance with ordering the tumor MMR testing in the eligible patients.

\section{Data Collection}

After approval by the Institutional Review Board, patient demographics, tumor diagnosis, treatment details, family pedigree, tumor MMR status, and germline testing results were extracted from the medical records for the preintervention and postintervention periods. Preintervention baseline data were retrospectively collected across a 12 -month period before the intervention. Postintervention data were prospectively collected over the 12 -month period after the start date. A data extractor who was not a part of our study team collected the postintervention data, and data accuracy was ensured by review of $10 \%$ of the cases selected at random.

\section{Performance Measures and Outcomes}

The primary end point was the proportion of patients with CRC aged 50 or younger who had tumor molecular studies ordered for MMR status. Acceptable tumor testing included either IHC or MSI (or both),

\section{Order MSI/IHC Patients $<50$ Years}

1. ClinicStation order set: Gastrointestinal

2. Select "Biomarkers"

3. Complete form *IHC \& MSI by PCR*

4. Print, provider signs, fax to

\section{Call a genetic counselor for HELP}

Figure 3 Visual cue at the point-of-care. A visual cue was installed at the point-of-care to remind care providers to order tumor-based molecular screening for Lynch syndrome.

Abbreviations: IHC, immunohistochemistry study; MSI, microsatellite instability assay; PCR, polymerase chain reaction. performed on either biopsy or surgical resection tumor tissue. The secondary end points were defined as "returns of investment," and included the number of patients identified to be managed clinically as having LS and the total number of living first-degree and second-degree relatives who would stand to benefit from genetic testing results.

We additionally assessed 3 process adherence end points: (1) the number of those whose tumor studies were clinically interpreted as "suggestive" of LS, defined as patients with MSI-high tumors or who had loss of expression of any of the MMR genes on IHC; (2) the number of those with "suggestive" tumor studies who received genetic counseling and risk assessment; and (3) the number of patients who completed the germline mutation testing that had been recommended to them after receiving genetic counseling.

Interval feedback regarding these end points and performance measures were provided to participating health care providers during 2 multidisciplinary tumor boards at 1 month, 3 months, and 13 months after the start date. Only anonymized and aggregate data were provided.

\section{Statistical Analysis}

Categorical variables were reported as number and percentage, whereas continuous variables were summarized using median and range. Postintervention data were compared with baseline data using ANOVA for continuous variables and chi-square test for categorical variables. To assess the robustness of the postintervention change, the primary end point was examined overall and in subgroups by the discipline (ie, medical vs surgical oncology, vs other). Process variation was prospectively analyzed using a process control chart (p-chart). All data were analyzed using SPSS Statistics version 21 (IBM Inc, New York, NY). All P values were 2 -sided, and statistical significance was designated as .05 .

\section{Results}

A total of 655 eligible young patients with CRC were assessed in this study: 356 patients during the 12-month preintervention period and 299 patients during the postintervention phase. Median age was 42 years in both the preintervention and postintervention groups (Table 1). Other demographic characteristics were also similar except for a slightly higher proportion of white patients in the postintervention group. Tumor characteristics, including tumor loca- 
QI Trial for Genetic Screening

tion and disease stage at presentation, did not significantly differ. In both groups, medical oncology was the portal of entry for most of the patients (Table 1).

At baseline (preintervention), 220 eligible patients $(61.8 \%)$ had tumor molecular testing (either IHC or MSI) as a screening test for LS: IHC was ordered in 211 patients $(59.3 \%)$ and MSI in 124 patients $(34.8 \%)$. After the intervention (postintervention), a remarkable testing rate of $94.25 \%$ (either IHC or MSI), with $94.25 \%$ for IHC and $67.82 \%$ for

\begin{tabular}{|c|c|c|c|}
\hline & $\begin{array}{l}\text { Before } \\
\text { Intervention } \\
(\mathrm{N}=356)\end{array}$ & $\begin{array}{l}\text { After } \\
\text { Intervention } \\
(\mathrm{N}=299)\end{array}$ & $\begin{array}{l}P \\
\text { Value }\end{array}$ \\
\hline \multicolumn{4}{|l|}{ Age, y } \\
\hline Mean, SD & $42.4 \pm 6.1$ & $42.2 \pm 6.61$ & .6437 \\
\hline $\begin{array}{l}\text { Median (range), } \\
\text { interquartile } \\
\text { range }\end{array}$ & $\begin{array}{c}44(19-49) \\
39-47\end{array}$ & $\begin{array}{c}44(18-50) \\
39-47\end{array}$ & \\
\hline \multicolumn{3}{|l|}{ Sex } & .903 \\
\hline Male & $190(53.37 \%)$ & $161(53.85 \%)$ & \\
\hline Female & $166(46.63 \%)$ & $138(46.15 \%)$ & \\
\hline \multicolumn{3}{|l|}{ Race } & .037 \\
\hline White & $241(67.70 \%)$ & $224(74.92 \%)$ & \\
\hline Black & 37 (10.39\%) & $21(7.02 \%)$ & \\
\hline Hispanic & $54(15.17 \%)$ & $28(9.36 \%)$ & \\
\hline Other & $24(6.74 \%)$ & $26(8.70 \%)$ & \\
\hline \multicolumn{3}{|l|}{ Tumor site } & .645 \\
\hline Proximal colon & $95(26.69 \%)$ & $92(30.77 \%)$ & \\
\hline Distal colon & $123(34.55 \%)$ & $92(30.77 \%)$ & \\
\hline Rectum & $133(37.36 \%)$ & $111(37.12 \%)$ & \\
\hline Other & $5(1.40 \%)$ & $4(1.34 \%)$ & \\
\hline \multicolumn{3}{|l|}{ Home service } & .125 \\
\hline Medical oncology & $242(67.98 \%)$ & $220(73.58 \%)$ & \\
\hline Surgical oncology & $93(26.12 \%)$ & $70(23.41 \%)$ & \\
\hline Other & $21(5.90 \%)$ & $9(3.01 \%)$ & \\
\hline \multicolumn{3}{|l|}{ Reason for visit } & .364 \\
\hline $\begin{array}{l}\text { New diagnosis, } \\
\text { surgical } \\
\text { treatment }\end{array}$ & $69(19.38 \%)$ & $71(23.75 \%)$ & \\
\hline $\begin{array}{l}\text { Adjuvant } \\
\text { treatment }\end{array}$ & $47(13.20 \%)$ & $29(9.70 \%)$ & \\
\hline Metastatic & $222(62.36 \%)$ & $184(61.54 \%)$ & \\
\hline Other & $18(5.06 \%)$ & $15(5.02 \%)$ & \\
\hline \multicolumn{3}{|c|}{ Disease stage at presentation } & .270 \\
\hline $\begin{array}{l}\text { Stage I } \\
\text { (Tis/T1/2,N0) }\end{array}$ & $19(5.43 \%)$ & $12(4.01 \%)$ & \\
\hline Stage II $(T 3 / 4, N 0)$ & $21(5.90 \%)$ & $24(8.03 \%)$ & \\
\hline Stage III (Tany, N+) & $64(17.98 \%)$ & $67(22.41 \%)$ & \\
\hline $\begin{array}{l}\text { Stage IV } \\
\text { (Tany,Nany,M+) }\end{array}$ & $252(70.79 \%)$ & $196(65.55 \%)$ & \\
\hline
\end{tabular}

MSI, was observed during the initial 3 months during which the active audit occurred. After longerterm follow-up, aggregate data over the 12 months after intervention showed that among 299 eligible patients, $83.3 \%$ had at least one test ordered, with IHC ordered on 244 patients (81.6\%) and MSI in 159 patients $(53.2 \%)$. Therefore, an absolute improvement of $21.5 \%$ was observed after intervention overall $(P<.001$; Table 2$)$. Although variations were observed, the sustained rate of tumor molecular screening testing significantly improved when compared with baseline (Figure 4). We further found that the intervention affected both medical and surgical oncology services because the rate of screening increased from $61.60 \%$ to $84.54 \%$ and $68.80 \%$ to $85.70 \%$, respectively.

Among the process adherence end points, 20 patients $(5.6 \%$ of 356$)$ in the preintervention group were found to have tumor molecular characteristics "suggestive" of LS. In the postintervention group, 23 such patients $(7.7 \%$ of 299 ) were identified (Table 3). Most patients with "suggestive" tumor studies were referred to and received genetic counseling and risk assessment (Table 3).

Of the patients with suggestive tumor characteristics, 13 and 10 underwent germline testing in the preintervention and postintervention groups, respectively. In addition to the patients identified with mutations, family members may potentially benefit from such genetic testing. Collectively, the health information from the 20 patients identified to be clinically managed as LS in the preintervention period could potentially be informative, because a total of 180 firstdegree and second-degree relatives were alive at the time (Table 3). The corresponding number increased to 202 in the postintervention period (Table 3).

\begin{tabular}{|c|c|c|c|}
\hline & $\begin{array}{l}\text { Before } \\
\text { Intervention } \\
(\mathrm{N}=356)\end{array}$ & $\begin{array}{l}\text { After } \\
\text { Intervention } \\
(\mathrm{N}=299)\end{array}$ & $P$ Value \\
\hline IHC ordered & $211(59.3 \%)$ & $244(81.61 \%)$ & $<.0001$ \\
\hline IHC resulted & 207 & 232 & \\
\hline MSI ordered & $124(34.8 \%)$ & $159(53.2 \%)$ & $<.0001$ \\
\hline MSI resulted & 102 & 137 & \\
\hline $\begin{array}{l}\text { Either IHC or MSI } \\
\text { ordered }\end{array}$ & $220(61.8 \%)$ & $250(83.6 \%)$ & $<.0001$ \\
\hline
\end{tabular}

Abbreviations: IHC, immunohistochemistry; MSI, microsatellite instability. 

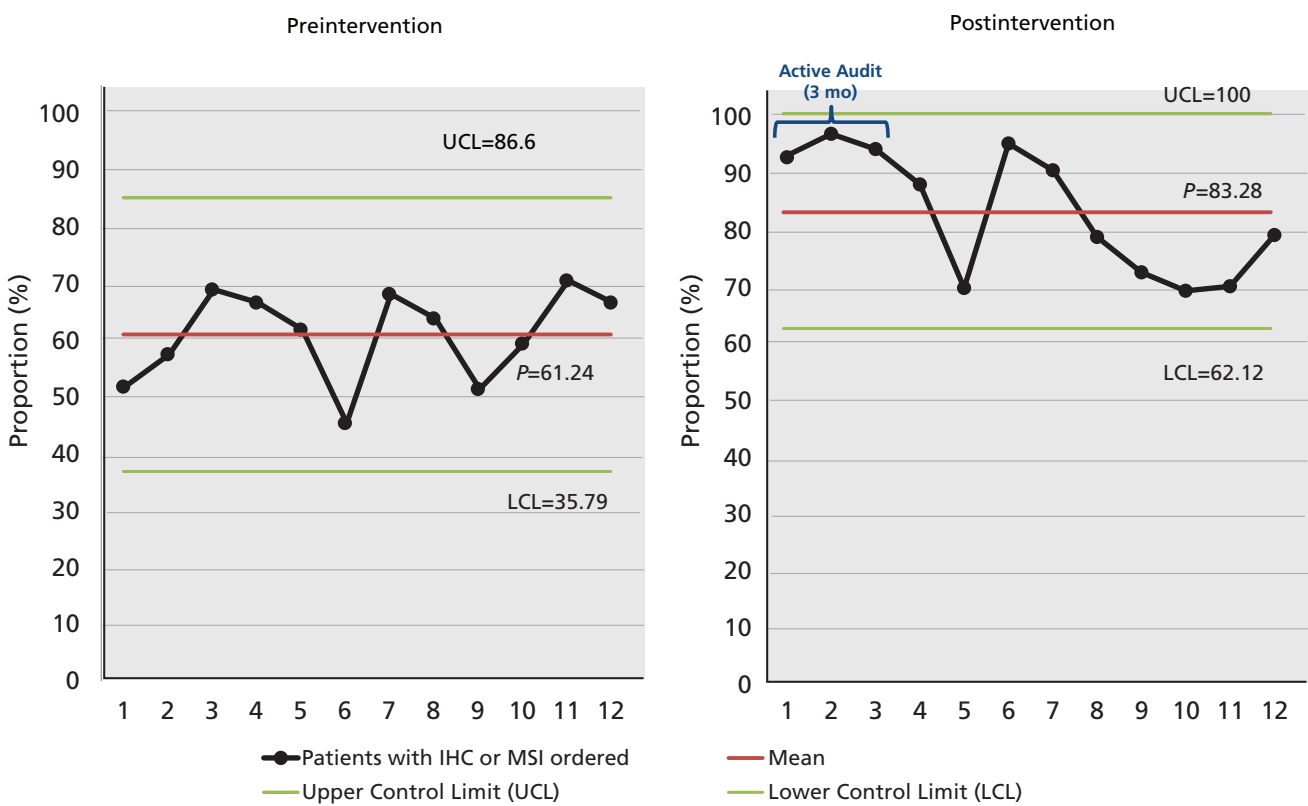

Figure 4 Proportion of eligible patients who had tumor-based molecular screening for Lynch syndrome. Process control chart illustrating those who had tumor-based molecular screening by immunohistochemistry study (IHC) or microsatellite instability assay (MSI) for Lynch syndrome during the preintervention period (12 mo, left) and the postintervention period (12 mo, right). The upper confidence limit (UCL; green), lower confidence limit (LCL; green), and process mean (red) over time are depicted. The mean proportion of patients screened was $61.8 \%$ (preintervention) and increased to a sustained $83.3 \%$ (postintervention; $P<.01$ ).

\section{Discussion}

Providing patient-centered care is 1 of the 6 major areas of health care quality improvement as defined by the IOM. Patient-centered care for young adults with $\mathrm{CRC}$ (age $\leq 50$ years) includes an appropriate genetic workup, because the genetic information enables patients to make decisions about future health care for themselves and their family members. Despite existing guidelines for universal tumor-based molecular screening for LS, implementation and adherence to them have been difficult in real practice. We reported a prospective intervention trial designed within the framework of Six Sigma quality improvement that significantly improved adherence to NCCN Guidelines for CRC Screening from $61.8 \%$ to a sustained $83.0 \%$. We further demonstrated increased detection of patients who should be clinically managed as having LS from $4.77 \%$ to $6.68 \%$, along with benefits to 202 living first- or second-degree relatives. With tumor molecular testing becoming more commonly recommended for cancer care, this report presents a prototype intervention study for optimizing the implementation of molecular diagnostics and for improving patient-centered care.
The clinical impact of our intervention was significant and can be measured based on 3 aspects of return on investment. First, we directly benefited young adults with CRC by providing them with

\begin{tabular}{|c|c|c|}
\hline Characteristic & $\begin{array}{l}\text { Before } \\
\text { Intervention } \\
(\mathrm{N}=356)\end{array}$ & $\begin{array}{l}\text { After } \\
\text { Intervention } \\
(\mathrm{N}=299)\end{array}$ \\
\hline $\begin{array}{l}\text { Suggestive result from } \\
\text { either IHC or MSI on } \\
\text { tumor }\end{array}$ & $20(5.6 \%)$ & $23(7.7 \%)$ \\
\hline $\begin{array}{l}\text { Suggestive tumor } \\
\text { result and had genetic } \\
\text { counseling }\end{array}$ & $18 / 20(90 \%)$ & $20 / 23(87 \%)$ \\
\hline $\begin{array}{l}\text { Suggestive tumor } \\
\text { result and had } \\
\text { germline mutation } \\
\text { testing }\end{array}$ & $13 / 20(65 \%)$ & $20 / 23(87 \%)$ \\
\hline $\begin{array}{l}\text { Living first-degree } \\
\text { relatives with potential } \\
\text { benefit from test results }\end{array}$ & 110 & 108 \\
\hline $\begin{array}{l}\text { Living first- or second- } \\
\text { degree with potential } \\
\text { benefit from test results }\end{array}$ & 180 & 202 \\
\hline
\end{tabular}

Abbreviations: IHC, immunohistochemistry testing; MSI, microsatellite instability testing. 
QI Trial for Genetic Screening

information regarding genetic risk. Many patients diagnosed with $\mathrm{CRC}$ at a young age struggle to understand the cause of their disease. Through universal tumor-based screening and confirmatory germline testing, we were able to identify a subgroup of patients whose disease could be explained by LS. They also gained information regarding LS screening recommendations, ${ }^{18,30}$ the risk of metachronous disease, $^{31}$ and options for risk-reducing surgery ${ }^{32}$ through genetic counseling and discussions. However, most of the patients whose disease was not consistent with LS were spared the concern about and emotional burden associated with hereditary CRC risk for their offspring and family members.

Second, a large number of family members with young patients with CRC could have been potentially impacted. First- and second-degree relatives gained information about their genetic risk for $\mathrm{CRC}$ as a result of the tumor tests performed during the preintervention and postintervention periods in this study. Family members of patients with LS could be further tested to elucidate whether they are a carrier of LS, whereas those patients without evidence of LS would be counseled regarding appropriate screening guidelines for individuals with a family history of sporadic CRC. Although not the main end point of this current intervention, a Familial High-Risk Gastrointestinal Cancer Clinic has been established at our institution, with the explicit purpose of facilitating further counseling and testing of probands and their family members.

Third and most importantly, our intervention led to a sustained impact over 12 months, suggesting that it was associated with a cultural and habitual change among the health care providers. Our educational intervention impacted providers at all levels within the care center. Visual cues at the point-of-care and the reminder e-mails during the first 3 months after the start date helped make tumor molecular testing a routine and habitual practice when encountering a young adult with CRC. Taken together, the greatest impact of the current intervention would be realized in the care of the future patients and their family members.

In order to apply the Six Sigma conceptual framework to improving patient-centered care and guideline adherence, the current process of genetic workup in young patients with CRC was analyzed. As the first target of intervention, we focused on increasing provider ordering of tumor-based screening for LS. Our interventions toward this single goal were able to improve the testing rate from $61.8 \%$ to a sustained $83.0 \%$, suggesting that it did account for most of the variation in practice. However, the still lessthan-universal testing rate highlights the conceptual framework of continuous improvement. A remaining $17 \%$ of patients did not undergo proper screening. The possible reasons may include many factors, including the high rate of metastatic disease in this population. Elucidating these reasons will form the target of future quality improvement studies. In particular, among the process-adherence secondary end points examined, confirmatory germline mutation testing was completed in only 13 of the 20 preintervention patients and only 20 of the 23 postintervention patients. Although this rate improved from $65 \%$ to $87 \%$, it remains suboptimal. Indeed, Heald et $\mathrm{al}^{33}$ recently reported patient-perceived lack of benefit as a common reason to decline genetic counseling, and we had previously demonstrated the educational impact of patient and family education in LS. ${ }^{34}$ Thus, we anticipate further educational interventions targeted at improving the rate of confirmatory germline testing for LS. Continued quality improvement cycles focused on other process-adherence end points to achieve even greater uniformity in the practice of tumor-based molecular screening for LS.

This study exemplified the successful application of a quality improvement conceptual framework for the adoption of guideline-recommended molecular testing. The application of such a conceptual framework to improve care has been slowly accumulating, ${ }^{24,35}$ but tumor molecular tests are increasingly used to guide cancer treatment and are being incorporated into NCCN Guidelines for CRC Screening. ${ }^{20,36,37}$ In our comparison of patients treated during 2 distinct (preintervention vs postintervention) periods, variance in practice simply because of changes over time could not be completely controlled. And it cannot be overlooked that the 3 months of active audit was associated with extremely high adherence rates, and that the ability to fully sustain this adherence will require additional permanent changes through continuous quality improvement. Building automated reminders or auditing mechanisms into the electronic medical record system would help sustain the favorable results of this intervention. Because the beneficial effects of this initiative are recognized within the multidisciplinary group, we anticipate a change in culture that will continue al- 
low this high adherence rate to continue. Evidence suggests that multifaceted approaches are more effective at changing physician behavior, and therefore we feel that our program of education, passive and active reminders, and dissemination of the benefits would accomplish this objective..$^{38,39}$

\section{Conclusions}

A prospective intervention designed with the Six Sigma conceptual framework improved adherence to the current guideline of universal genetic screening and led to identification of more patients and family members who would benefit from clinical management as LS. Genetic workup in young adults with CRC allows patients to understand disease risk and make informed treatment decisions. Our study represents a proof-ofconcept study in improving practical adherence to the increasing numbers of guidelines that involve molecular testing as the basis for oncologic care.

\section{References}

1. Institute of Medicine. Crossing the Quality Chasm: A New Health System for the 21st Century. Washington, DC: National Academies Press; 2001.

2. O'Connell JB, Maggard MA, Liu JH, et al. Rates of colon and rectal cancers are increasing in young adults. Am Surg 2003;69:866-872.

3. Ahnen DJ, Wade SW, Jones WF, et al. The increasing incidence of young-onset colorectal cancer: a call to action. Mayo Clin Proc 2014;89:216-224.

4. Siegel RL, Jemal A, Ward EM. Increase in incidence of colorectal cancer among young men and women in the United States. Cancer Epidemiol Biomarkers Prev 2009;18:1695-1698.

5. You YN, Xing Y, Feig BW, et al. Young-onset colorectal cancer: is it time to pay attention? Arch Intern Med 2012;172:287-289.

6. Hampel H. NCCN increases the emphasis on genetic/familial high-risk assessment in colorectal cancer. J Natl Compr Canc Netw 2014;12:829-831.

7. Lynch PM. When and how to perform genetic testing for inherited colorectal cancer syndromes. J Natl Compr Canc Netw 2013;11:1577-1583.

8. Ladabaum U, Wang G, Terdiman J, et al. Strategies to identify the Lynch syndrome among patients with colorectal cancer: a cost-effectiveness analysis. Ann Intern Med 2011;155:69-79.

9. Lynch HT, de la Chapelle A. Hereditary colorectal cancer. N Engl J Med 2003;348:919-932.

10. Moreira L, Balaguer F, Lindor N, et al. Identification of Lynch syndrome among patients with colorectal cancer. JAMA 2012;308:1555-1565.

11. Recommendations from the EGAPP Working Group: genetic testing strategies in newly diagnosed individuals with colorectal cancer aimed at reducing morbidity and mortality from Lynch syndrome in relatives. Genet Med 2009;11:35-41.

12. Beamer LC, Grant ML, Espenschied CR, et al. Reflex immunohistochemistry and microsatellite instability testing of colorectal tumors for Lynch syndrome among US cancer programs and follow-up of abnormal results. J Clin Oncol 2012;30:1058-1063.

13. Mvundura M, Grosse SD, Hampel H, et al. The cost-effectiveness of genetic testing strategies for Lynch syndrome among newly diagnosed patients with colorectal cancer. Genet Med 2009;12:93-104.

14. Sturgeon D, McCutcheon $T$, Geiger TM, et al. Increasing Lynch syndrome identification through establishment of a hereditary colorectal cancer registry. Dis Colon Rectum 2013;56:308-314.
15. Provenzale D, Jasperson K, Ahnen DJ, et al. NCCN Clinical Practice Guidelines in Oncology: Colorectal Cancer Screening. Version 1, 2015. Available at: NCCN.org. Accessed June 15, 2015.

16. Lindor NM, Petersen GM, Hadley DW, et al. Recommendations for the care of individuals with an inherited predisposition to Lynch syndrome: a systematic review. JAMA 2006;296:1507-1517.

17. Weissman SM, Burt R, Church J, et al. Identification of individuals at risk for Lynch syndrome using targeted evaluations and genetic testing: National Society of Genetic Counselors and the Collaborative Group of the Americas on Inherited Colorectal Cancer joint practice guideline. J Genet Couns 2012;21:484-493.

18. Burt RW, Cannon JA, David DS, et al. Colorectal cancer screening. J Natl Compr Canc Netw 2013;11:1538-1575.

19. Burt RW, Barthel JS, Dunn KB, et al. NCCN Clinical Practice Guidelines in Oncology. Colorectal cancer screening. J Natl Compr Canc Netw 2010;8:8-61.

20. Benson AB III, Venook AP, Bekaii-Saab T, et al. Colon cancer, version 3.2014. J Natl Compr Canc Netw 2014;12:1028-1059.

21. Anning L, Koo N, Neely J, et al. Management of young onset colorectal cancer: divergent practice in the East of England. Colorectal Dis 2011;13:e297-302.

22. Singh H, Schiesser R, Anand G, et al. Underdiagnosis of Lynch syndrome involves more than family history criteria. Clin Gastroenterol Hepatol 2010;8:523-529.

23. Overbeek LI, Hoogerbrugge N, van Krieken JH, et al. Most patients with colorectal tumors at young age do not visit a cancer genetics clinic. Dis Colon Rectum 2008;51:1249-1254.

24. Nicolay CR, Purkayastha S, Greenhalgh A, et al. Systematic review of the application of quality improvement methodologies from the manufacturing industry to surgical healthcare. Br J Surg 2012;99:324-335.

25. Sedlack JD. The utilization of six sigma and statistical process control techniques in surgical quality improvement. J Healthc Qual 2010;32:18-26.

26. Chassin MR. Is health care ready for Six Sigma quality? Milbank Q 1998;76:565-591, 510.

27. Aboelmagd MG. Six Sigma quality: a structured review and implications for future research. Int J Qual Reliab Manage 2010;27:268-317.

28. Khan MH, Howard TJ, Fogel EL, et al. Frequency of biliary complications after laparoscopic cholecystectomy detected by ERCP: experience at a large tertiary referral center. Gastrointest Endosc 2007;65:247-252.

29. Frankel HL, Crede WB, Topal JE, et al. Use of corporate Six Sigma performanceimprovement strategies to reduce incidence of catheter-related bloodstream infections in a surgical ICU. J Am Coll Surg 2005;201:349-358.

30. Vasen HFA, Abdirahman M, Brohet $R$, et al. One to 2-year surveillance intervals reduce risk of colorectal cancer in families with Lynch syndrome. Gastroenterology 2010;138:2300-2306.

31. Parry S, Win AK, Parry B, et al. Metachronous colorectal cancer risk for mismatch repair gene mutation carriers: the advantage of more extensive colon surgery. Gut 2010;60:950-957.

32. Schmeler KM, Lynch HT, Chen LM, et al. Prophylactic surgery to reduce the risk of gynecologic cancers in the Lynch syndrome. N Engl J Med 2006;354:261-269.

33. Heald B, Plesec T, Liu X, et al. Implementation of universal microsatellite instability and immunohistochemistry screening for diagnosing lynch syndrome in a large academic medical center. J Clin Oncol 2013;31:1336-1340.

34. Bannon SA, Mork M, Vilar E, et al. Patient-reported disease knowledge and educational needs in Lynch syndrome: findings of an interactive multidisciplinary patient conference. Hered Cancer Clin Pract 2014;12:1.

35. Vest JR, Gamm LD. A critical review of the research literature on Six Sigma, Lean and StuderGroup's Hardwiring Excellence in the United States: the need to demonstrate and communicate the effectiveness of transformation strategies in healthcare. Implement Sci 2009;4:35.

36. Coit DG, Andtbacka R, Anker CJ, et al. Melanoma, version 2.2013: featured updates to the NCCN guidelines. J Natl Compr Canc Netw 2013;11:395-407.

37. Theriault RL, Carlson RW, Allred C, et al. Breast cancer, version 3.2013 featured updates to the NCCN guidelines. J Natl Compr Canc Netw 2013;11:753-760; quiz 761.

38. Greene RA, Beckman H, Chamberlain J, et al. Increasing adherence to a community-based guideline for acute sinusitis through education, physician profiling, and financial incentives. Am J Manag Care 2004;10:670-678.

39. Grol R. Improving the quality of medical care: building bridges among professional pride, payer profit, and patient satisfaction. JAMA 2001;286:25782585 . 